\title{
Fusarium graminearum Tri12p Influences Virulence to Wheat and Trichothecene Accumulation
}

\author{
Jon Menke, ${ }^{1}$ Yanhong Dong, ${ }^{1}$ and H. Corby Kistler ${ }^{1,2}$ \\ ${ }^{1}$ Department of Plant Pathology, University of Minnesota, St. Paul 55108, U.S.A.; ${ }^{2}$ United States Department of Agriculture- \\ Agricultural Research Service Cereal Disease Laboratory, 1551 Lindig Street, St. Paul, MN 55108, U.S.A.
}

Submitted 6 April 2012. Accepted 13 July 2012.

\begin{abstract}
The gene Tri12 encodes a predicted major facilitator superfamily protein suggested to play a role in export of trichothecene mycotoxins produced by Fusarium spp. It is unclear, however, how the Tri12 protein (Tri12p) may influence trichothecene sensitivity and virulence of the wheat pathogen Fusarium graminearum. In this study, we establish a role for Tri12 in toxin accumulation and sensitivity as well as in pathogenicity toward wheat. Tri12 deletion mutants (tri12) are reduced in virulence and result in decreased trichothecene accumulation when inoculated on wheat compared with the wild-type strain or an ectopic mutant. Reduced radial growth of tril2 mutants on trichothecene biosynthesis induction medium was observed relative to the wild type and the ectopic strains. Diminished trichothecene accumulation was observed in liquid medium cultures inoculated with tri12 mutants. Wild-type fungal cells grown under conditions that induce trichothecene biosynthesis develop distinct subapical swelling and form large vacuoles. A strain expressing Tri12p linked to green fluorescent protein shows localization of the protein consistent with the plasma membrane. Our results indicate Tri12 plays a role in self-protection and influences toxin production and virulence of the fungus in planta.
\end{abstract}

The plant pathogen Fusarium graminearum presents a twofold threat to agriculture and consumers. Not only does this filamentous fungus cause Fusarium head blight (FHB) disease that results in significant yield loss in wheat and barley, it also taints these grains with potent mycotoxins harmful to humans, animals, and plants alike. Grain may even appear to be physically sound while still being significantly contaminated with trichothecene mycotoxins (Hollingsworth et al. 2008). F. graminearum produces the type $\mathrm{B}$ trichothecene mycotoxin deoxyni-

Nucleotide sequence data is available in the GenBank database under accession number JF809795.

The mention of firm names or trade products does not imply that they are endorsed or recommended by the United States Department of Agriculture (USDA) over other firms or similar products not mentioned. The USDA is an equal opportunity provider and employer.

Corresponding author: H. Corby Kistler; Telephone: 612-625-9774; Fax: 651-649-5054; E-mail: hckist@umn.edu

* The $e$-Xtra logo stands for "electronic extra" and indicates that 11 supplementary figures, five supplementary tables, and eight supplementary videos are published online.

This article is in the public domain and not copyrightable. It may be freely reprinted with customary crediting of the source. The American Phytopathological Society, 2012. valenol (DON) and its acetylated derivatives, 15-acetyldeoxynivalenol (15ADON) and 3-acetyldeoxynivalenol (3ADON), or the related trichothecene nivalenol (NIV). Trichothecene mycotoxins are demonstrated virulence factors in wheatFusarium spp. interactions (Proctor et al. 1995) and increased trichothecene accumulation is associated with increased fungal virulence (Gardiner et al. 2010; Goswami and Kistler 2005). Absent the ability to produce trichothecenes, $F$. graminearum is unable to cause symptoms of FHB beyond an initially infected wheat spikelet (Bai et al. 2002).

Significant progress has been made in identifying genes involved in the biosynthesis of trichothecenes, including those encoding enzymes for trichothecene biosynthesis itself and transcription factors controlling toxin gene regulation. Most of these proteins are encoded within a single major biosynthetic gene cluster (Tri cluster) whereas other genes are located on separate chromosomes outside of the main cluster (Rep and Kistler 2010). The exact role some of these proteins play in trichothecene biosynthesis remains unknown, and there may be proteins involved in synthesis that have yet to be identified (Kimura et al. 2007). The cellular location of trichothecene biosynthesis within fungal cells, how cells deal with the toxic effect of trichothecenes, and how trichothecenes exit cells are unknown.

ATP-binding cassette (ABC) and major facilitator superfamily (MFS) transport proteins are important for some fungi to colonize plants and cause disease. These transporters can act as virulence or pathogenicity factors by providing protection from the toxic secondary metabolites produced by plants or by transport of toxins produced by the fungus itself (Coleman and Mylonakis 2009). ABC transporters are proposed to be involved in the export of secondary metabolites and tolerance to inhibitory substances in the environment such as fungicides or plantproduced antimicrobial products. ZRAl encodes a putative $\mathrm{ABC}$ transporter that is required for the production of zearalenone by $F$. graminearum (Lee et al. 2011). MFS proteins are involved in transport of endogenous toxic secondary metabolites. MFS proteins have been shown to provide for export of host-specific and nonspecific toxins diacetoxyscirpenol, HCtoxin, and cercosporin in Fusarium sporotrichioides, Cochliobolus carbonum, and Cercospora kikuchii or Cercospora nicotianae, respectively (Alexander et al. 1999; Callahan et al. 1999; Choquer et al. 2007; Pitkin et al. 1996).

Characterization of Tri12 in F. sporotrichioides (FsTri12) demonstrated that FsTri12p, an MFS transporter, plays a role in trichothecene efflux (Alexander et al. 1999). A strain with a mutation in the FsTril2 gene produced 97\% less T-2 toxin than the wild type and exhibited reduced radial growth in the presence of the precursor trichothecene, diacetoxyscripenol. FsTri12p also increased trichothecene flux in transgenic Sac- 
charomyces cerevisiae. Nevertheless, the transgenic yeast strain expressing FsTril2 was not greatly protected from the toxic effects of diacetoxyscripenol; therefore, it was concluded that FsTri12 plays only a minor role in resistance to trichothecenes (Alexander et al. 1999).

The exact function of Tril2 in F. graminearum (FgTril2) is unknown. The objectives of this study were to i) establish an accurate gene model for FgTri12, ii) determine whether FgTri12 promotes trichothecene tolerance in $F$. graminearum and contributes to fungal virulence and toxin production in planta, and iii) localize FgTri12p within cells during trichothecene biosynthesis. This study is the first to report the temporal and spatial localization patterns of FgTri12p and to report its influence on virulence in $F$. graminearum.

\section{RESULTS}

$3^{\prime}$ Rapid amplification of cDNA ends and cDNA sequencing.

The two most commonly used sources of annotation for the F. graminearum genome, the Munich Information Center for Protein Sequences (MIPS) and Broad Institute databases (Cuomo et al. 2007; Güldener et al. 2006; Wong et al. 2011), differ in their predictions for FgTri12. Although both predictions agree upon the $5^{\prime}$ start site and the position of the first two introns, the models differ considerably in the $3^{\prime}$ region. To resolve these discrepancies, cDNA of FgTril2 transcripts were synthesized via $3^{\prime}$ rapid amplification of cDNA ends (RACE). A polymerase chain reaction (PCR) amplicon spanning 2,229 bp from the $3^{\prime}$ end of the FgTril2 transcript was sequenced (GenBank accession JF809795) (Supplementary Fig. S1). The sequenced cDNA matched perfectly with FgTril2 genomic DNA for exon regions. The sequence also confirmed the presence and genetic location of the first two introns predicted by both gene models but disagreed with both the Broad and MIPS gene annotations at the $3^{\prime}$ terminus. The cDNA indicated that a third intron is present in the protein-coding region of this gene; a finding that was confirmed by an expressed sequence tag (EST) available in GenBank (CD456153). Two additional EST (BI950733 and gi|13621077) also support the presence and location of the first two predicted introns.

\section{Pairwise alignment and analysis of DNA and amino acid sequences.}

Pairwise alignment of Tri12 DNA sequences from $F$. graminearum (FgTri12) and $F$. sporotrichioides (FsTri12) revealed $80.5 \%$ nucleotide identity between the coding sequences. The locations of the first and second introns of FgTri12 are consistent with those predicted for FsTri12. The third intron of FsTril2 lies entirely within the $3^{\prime}$ untranslated region of the gene, whereas the final exon of FgTril2 encodes a single base pair of the protein's final amino acid and the translational stop codon. Remarkably, the immediate $3^{\prime}$ flanking region of both FsTril2 and FgTril2 are predicted to overlap the promoter region of the adjacent Trill gene in both $F$. graminearum and $F$. sporotrichioides, with the polyadenylation sequence of the FgTril2 transcript found only $70 \mathrm{bp}$ upstream of the predicted translational start of FgTril1. FgTril2 and FsTril2 are predicted to encode 600 and 598 amino acid proteins, respectively, sharing $78.1 \%$ amino acid identity and $89.4 \%$ similarity.

Transmembrane domain predictions indicate that both $F$. graminearum Tri12p (FgTri12p) and F. sporotrichioides Tri12p (FsTri12p) possess 14 membrane-spanning domains (Supplementary Fig. S2), consistent with a DHA14, $\mathrm{H}^{+}$: drug antiporter (Coleman and Mylonakis 2009). The model preferred by TMPred places both the carboxy and amino termini on the cytoplasmic side of the plasma membrane. Amino acid sequence conservation in predicted transmembrane domains of FgTri12p and FsTri12p varies considerably. The 14th predicted transmembrane domain of Tri12p is completely conserved among all DON- and NIV-producing strains of $F$. graminearum and T-2producing strains of $F$. sporotrichioides. The amino acid sequence that underlies the fifth predicted transmembrane domain displays a high degree of variability with several chemotypespecific polymorphisms (Supplementary Fig. S3).

\section{FgTri12 is required for wild-type pathogenicity, trichothecene accumulation, and trichothecene tolerance.}

FgTri12 deletion mutants (PH-1tri12) were generated in the wild-type strain $\mathrm{PH}-1$ by split-marker recombination mutagenesis (Supplementary Fig. S4). A strain with an ectopic insertion of the split-marker constructs was also selected for analysis (PH-1ectopic). Southern hybridization confirmed the presence of the selectable marker $(h p h)$ in transformants and the presence or absence of FgTri12 in PH-1, PH-1tri12A, PH-1tri12B, $\mathrm{PH}-1$ tri12C, and PH-1ectopic strains (Supplementary Fig. S5). Reverse-transcriptase (RT)-PCR was used to confirm the expression of FgTril2 transcripts in $\mathrm{PH}-1$ and $\mathrm{PH}-1$ ectopic strains and the absence of transcripts in $\mathrm{PH}-1$ tril2 disruption mutants under conditions that induce trichothecene biosynthesis in culture (Supplementary Fig. S6).

The pathogenicity of $\mathrm{PH}-1$ tril2 mutants was consistently reduced compared with the wild-type or $\mathrm{PH}-1$ tril2 ectopic strain. All strains were assayed by point inoculation of wheat spikelets at anthesis and each was able to infect tissue, cause necrosis at the point of inoculation, and spread, causing disease symptoms beyond the inoculated spikelet. Pathogenicity was assessed from two perspectives. Inoculated spikes were detached and weighed immediately prior to the assessment of

Table 1. Pathogenicity and trichothecene concentrations in infected tissue

\begin{tabular}{|c|c|c|c|c|}
\hline \multirow[b]{2}{*}{ Strain } & \multicolumn{2}{|c|}{ Pathogenicity } & \multicolumn{2}{|c|}{ Trichothecene concentration $\left(\mu \mathrm{g} \mathrm{g}^{-1} \text { of dried infected tissue }\right)^{\mathrm{a}}$} \\
\hline & Mass of spike $(\mathrm{g})^{\mathbf{b}}$ & Number of spikelets ${ }^{\mathrm{c}}$ & DON & 15ADON \\
\hline PH-1 & $1.85 \pm 0.09$ & $5.7 \pm 0.4$ & $479.2 \pm 47.6$ & $47.6 \pm 8.9$ \\
\hline PH-1tri12A & $2.10 \pm 0.09^{d}$ & $3.9 \pm 0.3^{\mathrm{ef}}$ & $298.8 \pm 17.2^{\mathrm{g}}$ & $17.2 \pm 2.3^{\mathrm{h}}$ \\
\hline PH-1tri12B & $2.09 \pm 0.08^{d}$ & $4.0 \pm 0.3^{\text {ef }}$ & $380.1 \pm 26.4^{g}$ & $26.4 \pm 3.4^{\mathrm{h}}$ \\
\hline PH-1tri12C & $2.07 \pm .0 .06^{\mathrm{d}}$ & $3.9 \pm 0.3^{\text {ef }}$ & $321.8 \pm 22.8^{\mathrm{g}}$ & $22.8 \pm 2.7^{\mathrm{h}}$ \\
\hline PH-1ectopic & $1.86 \pm .0 .09$ & $4.7 \pm 0.4^{\mathrm{i}}$ & $449.6 \pm 31.1$ & $31.1 \pm 3.8$ \\
\hline
\end{tabular}

\footnotetext{
${ }^{a}$ Mean \pm SEM of the concentration of deoxynivalenol (DON) and 15-acetyldeoxynivalenol (15ADON) in the inoculated spikelet 10 days after inoculation

${ }^{\mathrm{b}}$ Mean \pm standard error of the mean (SEM) mass of symptomatic spikes 10 days after inoculation of a single central spikelet.

c Mean \pm SEM number of wheat spikelets per inflorescence exhibiting necrotic symptoms 10 days after inoculation of a single central spikelet.

${ }^{\mathrm{d}}$ Mean significantly greater than value for PH-1, Student's unpaired $t$ test $(P<0.05)$.

e Mean significantly less than value for PH-1, Mann-Whitney U test $(P<0.005)$.

${ }^{\mathrm{f}}$ Mean significantly less than value for PH-1ectopic, Mann-Whitney U test $(P<0.15)$.

g Mean significantly less than value for PH-1, Student's unpaired $t$ test $(P<0.05)$.

${ }^{\mathrm{h}}$ Mean significantly less than value for PH- 1 , Student's unpaired $t$ test $(P<0.0001)$.

${ }^{\mathrm{i}}$ Mean significantly less than value for PH-1, Mann-Whitney $\mathrm{U}$ test $(P<0.05)$.
} 
symptoms. The average mass of spikes inoculated with $\mathrm{PH}-$ 1 tri12 mutants was consistently higher than spikes inoculated with the PH-1 or PH-1ectopic strain. The mean mass of spikes inoculated with $\mathrm{PH}-1$ tril 2 disruption mutants was $13 \%$ greater than those inoculated with $\mathrm{PH}-1$ or $\mathrm{PH}-1$ ectopic strains due to the greater amount of healthy tissue in these spikes. Symptom assessment gave similar results. The mean number of symptomatic spikelets was consistently reduced in spikes inoculated with PH-1tril2 mutants compared with plants inoculated with PH-1 (Table 1). However, a slightly reduced number of symptomatic spikelets also was observed in spikes inoculated with $\mathrm{PH}-1$ ectopic compared with plants inoculated with $\mathrm{PH}-1$.

Infection of wheat with all strains resulted in the accumulation of DON and lesser amounts of 15ADON (Table 1). The PH-1tri12 mutants consistently accumulated significantly lower trichothecene concentrations in wheat than the wild type and PH-1ectopic; mean DON and 15ADON concentrations were significantly lower in spikelets inoculated with $\mathrm{PH}-1$ tril2 disruption mutants compared with those inoculated with $\mathrm{PH}-1$ or PH-1ectopic.

All strains grown in liquid trichothecene biosynthesis induction (TBI) medium resulted in higher levels of 15ADON than DON (Table 2). The mean 15ADON concentration was consistently lower in cultures inoculated with $\mathrm{PH}-1$ tril2 disruption mutants compared with those inoculated with $\mathrm{PH}-1$ or PH-1ectopic.

Growth of all $\mathrm{PH}-1$ tril2 mutants was reduced compared with wild-type and PH-1ectopic strains on TBI medium but not on medium where toxin does not accumulate. Radial growth of all strains was compared over $96 \mathrm{~h}$ on TBI agar medium (Supplementary Table S1). Growth of the PH-1tri12 mutants was reduced at $96 \mathrm{~h}$ when compared with $\mathrm{PH}-1$ and $\mathrm{PH}-1$ ectopic strains. Radial growth of all strains was similar on minimal medium (MM) under conditions where trichothecenes do not accumulate. These results indicate that FgTril2 is, at least in part, involved in overcoming self-inhibition by trichothecenes.

\section{Localization of Tri12p}

to the plasma membrane during toxin synthesis.

To determine its subcellular location during in vitro toxin biosynthesis, FgTri12 was tagged with enhanced green fluorescent protein $(e G F P)$ in the wild-type strain $\mathrm{PH}-1$. The tagging construct was engineered to produce the targeted protein with its carboxy terminus fused to eGFP (Supplementary Fig. $\mathrm{S} 7)$. Insertion of the $e G F P$ tagging construct was confirmed via Southern hybridization (Supplementary Fig. S8). Synthesis of a fusion protein was confirmed via Western blotting. Bound and free eGFP were detected in cell extracts after $36 \mathrm{~h}$ of

Table 2. Trichothecene concentrations in trichothecene biosynthesis induction medium

\begin{tabular}{llc}
\hline & \multicolumn{2}{c}{ Trichothecene concentration } \\
\cline { 2 - 3 } Strain & $\mathbf{1 5 A D O N ~}^{\mathbf{a}}$ & DON $^{\mathbf{b}}$ \\
\hline PH-1 & $37.6 \pm 1.5$ & $3.2 \pm 0.1$ \\
PH-1tri12A & $29.5 \pm 0.9^{\mathrm{c}}$ & $2.9 \pm 0.1^{\mathrm{c}}$ \\
PH-1tri12B & $31.4 \pm 0.9^{\mathrm{c}}$ & $2.8 \pm 0.1^{\mathrm{c}}$ \\
PH-1tri12C & $33.7 \pm 1.1^{\mathrm{c}}$ & $3.6 \pm 0.1^{\mathrm{d}}$ \\
PH-1ectopic & $36.9 \pm 1.9$ & $3.2 \pm 0.1$ \\
\hline
\end{tabular}

${ }^{\mathrm{a}}$ Mean \pm standard error of the mean (SEM) concentration of 15-acetyldeoxynivalenol (15ADON) in clarified culture medium 7 days after inoculation ( $\mu \mathrm{g} \mathrm{g}^{-1}$ of dried infected tissue).

${ }^{b}$ Mean \pm SEM concentration of deoxynivalenol (DON) in clarified culture medium 7 days after inoculation ( $\mu \mathrm{g} \mathrm{g}^{-1}$ of dried infected tissue).

${ }^{c}$ Mean significantly less than value for PH-1, Student's unpaired $t$ test $(P<$ $0.05)$.

${ }^{\mathrm{d}}$ Mean significantly greater than value for $\mathrm{PH}-1$, Student's unpaired $t$ test $(P<0.001)$. growth in TBI cultures, whereas only free eGFP was observed after $48 \mathrm{~h}$ (Supplementary Fig. S9). To determine whether the $e G F P$-tagged strain (PH-1Tri12::eGFP) differed phenotypically from the wild type, pathogenicity tests, radial growth assays, and in vitro and in planta trichothecene assays were conducted. No significant difference was observed in the mean number of symptomatic spikelets or mean mass of infected spikes on inoculated wheat, or the concentration of DON or $15 \mathrm{ADON}$ in planta (Supplementary Table S2). The eGFPtagged strain exhibited a very slight but significant increase in radial growth and decrease in $15 \mathrm{ADON}$ but not DON concentration on TBI medium (Supplementary Tables S3 and S4).

Growth of PH-1Tri12::eGFP was compared with wild-type PH-1 in shaken liquid TBI cultures via bright-field, differential interference contrast (DIC), and fluorescence microscopy. To observe differences in cell morphology, strains were grown from conidia in liquid TBI medium and MM (Fig. 1). No morphological differences were noted between strains during the entire time course. During the initial $18 \mathrm{~h}$ of growth, cell morphology was similar in TBI and minimal media. After $18 \mathrm{~h}$, large spherical organelles are evident only in cells grown in liquid TBI medium. After $36 \mathrm{~h}$ in TBI medium, certain cells swell, resulting in bulbous, ovoid structures that form behind the advancing hyphal tip. Bulbous subapical cells often branched, resulting in bifurcation of hyphae advancing from these cells. Other hyphae within TBI cultures thickened and also branched more frequently than in MM, resulting in a coralloid morphology (Fig. 2). Single or clusters of distinct spherical organelles also were observed within the ovoid subapical cells. The spherical organelles fluoresced upon treatment with 7amino-4-chloromethylcoumarin (CMAC), indicating that they are likely late endosomes or vacuoles (Fig. 3). By $40 \mathrm{~h}$ after inoculation in TBI, 15ADON and DON were present in both PH-1Tri12::eGFP and PH-1 cultures.

Fluorescence within PH-1Tri12::eGFP cells is observed approximately $18 \mathrm{~h}$ after suspension of spores in liquid TBI medium, yet only within the ovoid cells of hyphae exhibiting subapical swelling. At this stage of expression, eGFP localizes to punctuate intracellular vesicular structures $<1 \mu \mathrm{m}$ in diameter within a fenestrated membranous network (Fig. 3). Imaging of cells expressing Tri12::eGFP at this time revealed only limited movement of these structures (Supplementary Video S1). After $24 \mathrm{~h}$, eGFP fluorescence localizes to rapidly motile vesicles and the intracellular membranous network but is mostly at the periphery of the cell where, because of the Tri12p transmembrane structure, it is presumed to be within the plasma membrane (Fig. 3). Cells expressing eGFP were few in number and fluorescence usually was restricted to single ovoid cells or, at times, within adjacent cells (Fig. 3). Also at this stage, fluorescence appears within the lumen of vacuoles. Cell contact with cover slip or slide surfaces may influence Tri12::eGFP expression, because cells in contact with these surfaces appear more likely to fluoresce.

Over the next $18 \mathrm{~h}$, an increasing proportion of cells exhibited the fluorescent localization patterns observed at earlier time points. Vivid fluorescence was observed in vesicles, the plasma membrane, and, increasingly, in the larger spherical vacuoles (Supplementary Figure S10; Supplementary Videos S2 to S6). After $42 \mathrm{~h}$, select cells exhibit localization of Tri12p::eGFP solely to large stationary vacuoles and clusters of smaller stationary structures (Fig. 3). The clusters of smaller stationary organelles (as well as the larger vacuoles) fluoresce with CMAC dye and are considered to be either late endosomes or smaller vacuoles.

Several fusion events between fluorescent vesicles and larger organelles were observed. The fusion of a Tri12p::eGFP-tagged motile vesicle with the plasma membrane was recorded via 
time-lapse imaging (Supplementary Video S5). Following the fusion event, eGFP fluorescence appeared to diffuse within the area of the membrane where fusion occurred. We interpret this process as a result of exocytosis of Tri12p::eGFP-containing vesicles.

\section{Latrunculin A abolishes motility of vesicles labeled with Tri12p::eGFP.}

To determine whether processes involved in cellular targeting of FgTri12p were dependent on actin microfilaments, cells were treated with latrunculin A, an inhibitor of actin polymerization. Fluorescently labeled motile vesicles were not observed in fungal cells treated with latrunculin A (Supplementary Video S7), whereas these organelles were present in cells treated with the solvent carrier dimethyl sulfoxide (DMSO) alone. Motility of vesicles was reestablished after a latrunculin A wash-out and $4 \mathrm{~h}$ of incubation in recovery medium containing putrescine (Supplementary Video S8). Cells plated before and after latrunculin A treatment and after latrunculin A wash-out retained the ability to grow, though radial growth of latrunculin-A-treated and washed cells was considerably slower (Supplementary Fig. S11). Nevertheless, this test demonstrated that latrunculinA-treated cells remained viable and that loss of eGFP-motile vesicles was not caused by cell death.

\section{DISCUSSION}

\section{FgTri12 gene structure.}

The results of cDNA sequencing of FgTril2 underscore the importance of using a combination of genetic comparative analysis and transcript data to validate in silico gene models. The structure of FgTril2 determined by the cDNA sequencing, although at odds with gene models found in the MIPS and Broad Institute databases, directly supports the description of the
FgTri12 coding region predicted by a comparative genomics approach (Ward et al. 2002). Comparative analysis of FgTri12p and FsTri12p revealed a high degree of amino acid sequence conservation in many predicted transmembrane domains, especially domain number 14 , which was identical for all species

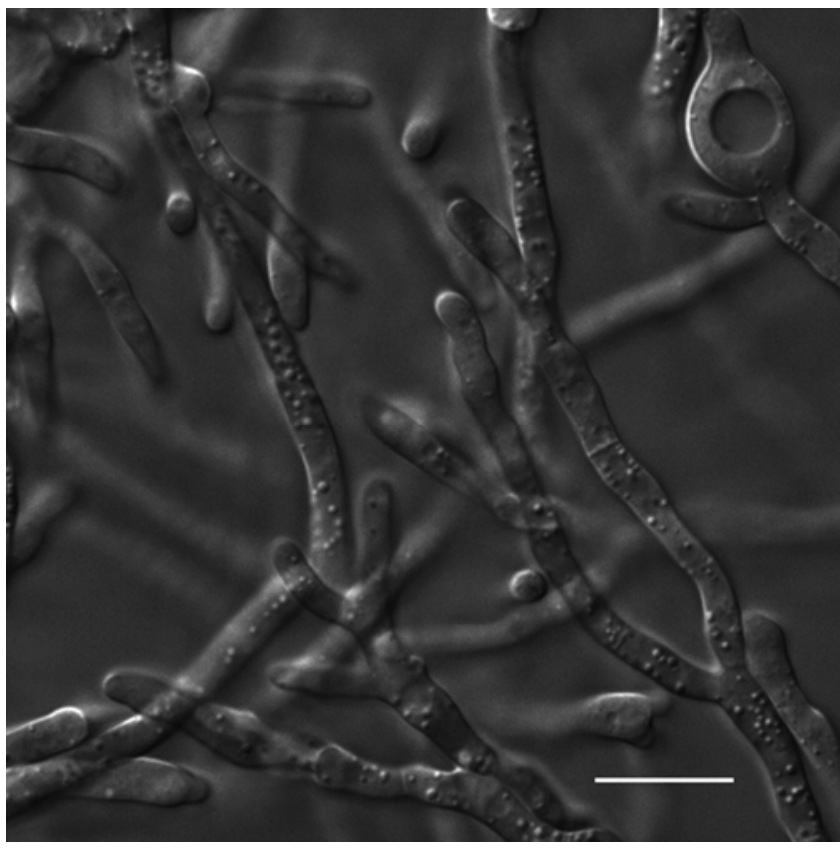

Fig. 2. Coralloid morphology of Fusarium graminearum hyphae grown in trichothecene biosynthesis induction medium. A differential interference contrast image of cells was obtained $36 \mathrm{~h}$ after a culture was inoculated with fresh conidia. Shaken cultures $(150 \mathrm{rpm})$ were incubated in total darkness at $25^{\circ} \mathrm{C}$. Scale bar $=10 \mu \mathrm{m}$.

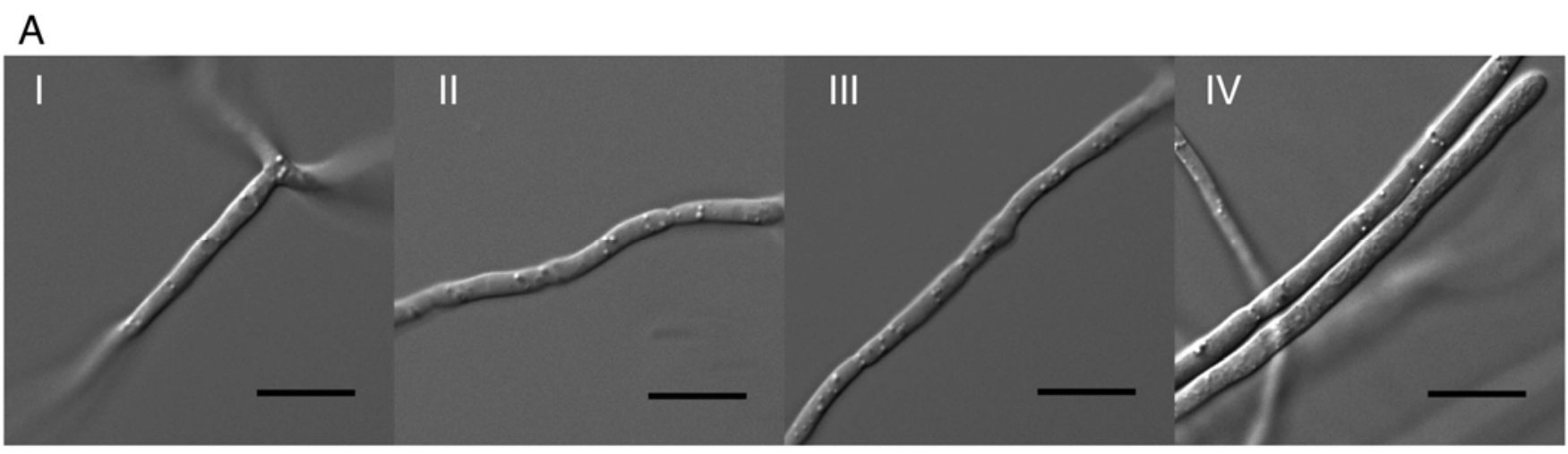

B

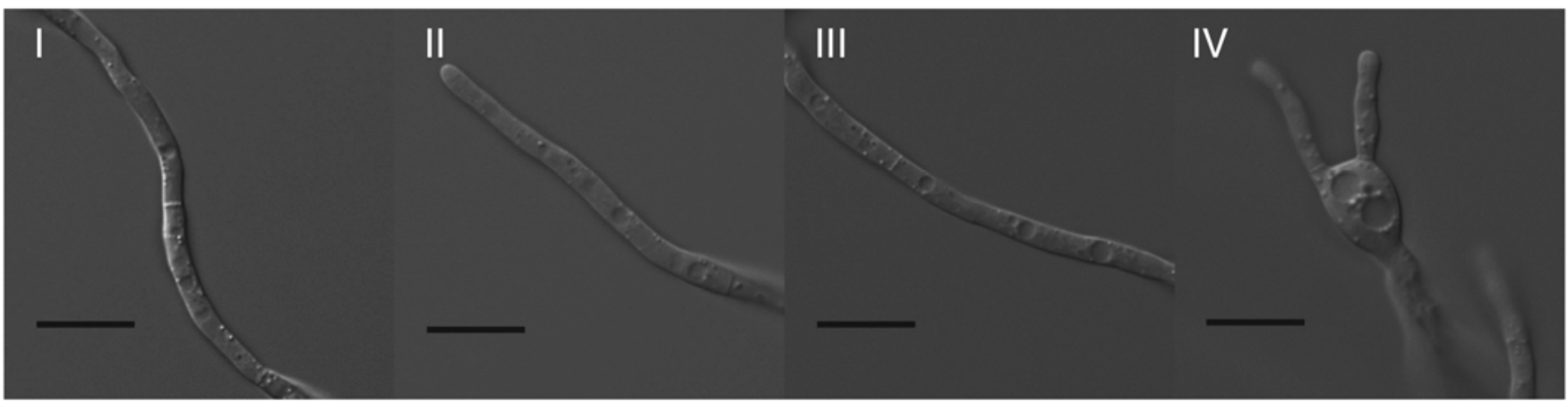

Fig. 1. Morphology of Fusarium graminearum mycelia grown in A, liquid minimal medium or B, trichothecene biosynthesis induction medium. Differential interference contrast images were taken at $12 \mathrm{~h}$ (I), $18 \mathrm{~h}$ (II), $24 \mathrm{~h}$ (III), and $36 \mathrm{~h}$ (IV) after cultures were inoculated with fresh macroconidia. Shaken cultures $(150 \mathrm{rpm})$ were incubated in total darkness at $25^{\circ} \mathrm{C}$. Scale bar $=10 \mu \mathrm{m}$. 
and chemotypes. Such strong conservation suggests a critical role of this domain in protein function. In contrast, other regions of the gene are more polymorphic with, in some instances, polymorphisms aligning with the chemotype of the producing strain.
Although the variation in chemical structures for trichothecenes is determined by allelic differences within biosynthetic enzymes, including those encoded by Tri7, Tri8, and Tril3 (Alexander et al. 2011; Lee et al. 2002), Tri12 also exhibits

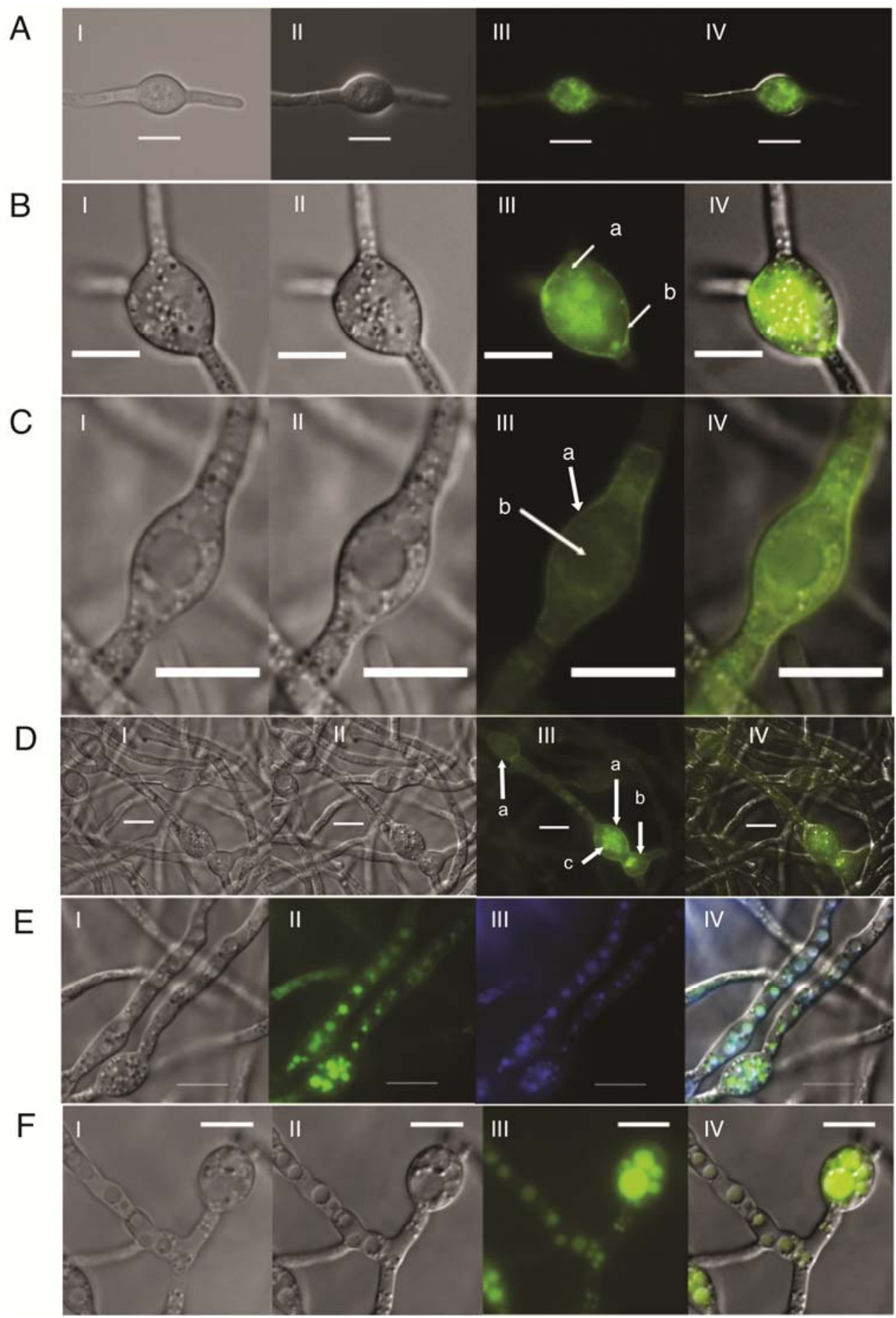

Fig. 3. A, Cell morphology and localization of Tri12p::eGFP to the subapical ovoid portion of an advancing hypha in trichothecene biosynthesis induction (TBI) liquid culture after $18 \mathrm{~h}$ of incubation at $28^{\circ} \mathrm{C}$ in total darkness. Bright field (I), differential interference contrast (DIC) (II), green fluorescent protein (GFP) (III), and DIC and GFP overlay images (IV) are shown. B, Cell morphology and Tri12p::eGFP localization after $24 \mathrm{~h}$ in TBI liquid culture. Bright field (I), DIC (II), GFP (III), and DIC and GFP overlay images (IV) of a swollen ovoid region of a cell near an advancing hyphal tip. Tri12p::eGFP localizes to motile vesicles (a) and the plasma membrane (b). C, Morphology and Tri12p::eGFP localization of a cell within a mature hyphal strand after $24 \mathrm{~h}$ in TBI liquid culture. Tri12p::eGFP localizes to the plasma membrane (a) but not to the vacuoles (b) of single mature ovoid cells. D, Cell morphology and Tri12p::eGFP localization among cells adjacent to swollen cells in TBI liquid culture after $24 \mathrm{~h}$ of incubation at $28^{\circ} \mathrm{C}$ in total darkness. Bright field (I), DIC (II), GFP (III), and DIC and GFP overlay images (IV) of four contiguous cells demonstrate sequential localization of Tri12p::eGFP to the plasma membrane (a), motile vesicles (b), and vacuoles (c). E, 7-Amino-4-chloromethylcoumarin (CMAC)-stained vacuoles and late endosomes in PH-1Tri12::eGFP cells from TBI cultures. DIC (I), GFP (II), CMAC (III), and CMAC, GFP, and DIC layered images (IV) taken after $42 \mathrm{~h}$ of incubation at $28^{\circ} \mathrm{C}$. F, Hyphal morphology and Tri12p::eGFP localization after $42 \mathrm{~h}$. Bright field (I), DIC (II), GFP (III), and GFP and DIC overlay images (IV) of mature ovoid cells and adjacent cells demonstrate that Tri12p::eGFP localizes primarily to vacuoles of various sizes. Scale bar $=10 \mu \mathrm{m}$. 
trans-species allelic polymorphism that tracks with chemotype (Ward et al. 2002). One potential explanation for the correlation between Tril2 polymorphism and chemotype is that chemotype-specific Tri12 alleles may occur due to genetic "hitchhiking" resulting from their proximity to Tri13, which biochemically determines the difference between NIV and DON chemotypes (Lee et al. 2002). This explanation seems unlikely because such chemotype-specific polymorphisms in Tri12 would have needed to persist through multiple speciation events. Additionally, within multiple species of the F. graminearum species complex, Tri12 polymorphisms do not appear to occur randomly and, in fact, are highly localized, especially in transmembrane domain number five. For other MFS transporters, transmembrane domain five has been shown to be important for substrate specificity (Pasrija et al. 2007). Therefore, it is reasonable to speculate that the chemotype-correlated polymorphisms in Tri12p transmembrane domain five may allow preferential transport of particular trichothecene molecules. It is unclear whether chemotype-specific polymorphisms might also explain the different properties of FgTri12p and FsTri12p with respect to regulation of toxin accumulation. In F. sporotrichioides, the deletion of Tri12 results in severe attenuation of trichothecene accumulation in culture, whereas the deletion of Tril2 in F. graminearum results in relatively modest reduction of trichothecene accumulation.

\section{Influence of Tri12p \\ in pathogenicity and trichothecene accumulation.}

MFS proteins play diverse roles in fungal tolerance toward endogenous secondary metabolites and xenobiotics. FgTri12p plays a similar role in self-protection toward trichothecenes for both $F$. sporotrichioides (Alexander et al. 1999) and $F$. graminearum. Tri12 mutants of both species grow more slowly than the wild type under trichothecene biosynthesis-inducing conditions but not under conditions where trichothecenes are not induced. Less trichothecene accumulates in wheat inoculated with an $F$. graminearum Tri12 mutant than in the wild type, and there is less disease. These observations are consistent with the proposed role of Tri12p in self-protection to trichothecenes. A reduction in the ability of the fungus to protect itself from the effects of trichothecenes in planta likely results in reduced growth and less disease. This decrease in virulence establishes that its role in disease is significant, though it is likely not the only tolerance mechanism that $F$. graminearum employs. Seong and associates (2009) reported that genes encoding four predicted $\mathrm{ABC}$ transporters and an MFS transporter were upregulated during wheat infection and that these genes were under the control of the trichothecene cluster transcriptional regulator Tri6. Two complementary mechanisms for tolerance to the same anti-fungal plant metabolite recently have been described for Nectria haematococca ( $F$. solani) and each system contributes incrementally to virulence of the fungus toward pea (Coleman et al. 2011). A genetically linked MFS transporter (PEP5) also was previously found to quantitatively affect virulence in this fungus toward pea (Han et al. 2001).

Interestingly, greater concentrations of $15 \mathrm{ADON}$ than DON accumulate in TBI cultures for all strains whereas, in inoculated spikelets of wheat, more DON than 15ADON accumulates. These results suggest that i) wheat may possess a mechanism that can convert $15 \mathrm{ADON}$ produced by the fungus in planta into DON or ii) in planta growth may cause $F$. graminearum to produce more DON. The PH-1tril2 mutants produced moderately reduced levels of trichothecenes in liquid TBI cultures compared with $\mathrm{PH}-1$. This result is in contrast with that obtained for $F$. sporotrichioides, where a striking reduction of T-2 (approximately 97\%) and no diacetoxyscirpenol was observed for the FsTri12 mutant grown in toxin-inducing medium (Alexander et al. 1999). The mechanism by which Tri12 genes in these different species differentially influence trichothecene accumulation is unclear. Expression of the FsTri12 in yeast demonstrated its role in trichothecene flux in a living system (Alexander et al. 1999). FsTri12 increased flux of trichothecene pathway intermediates 15-decalnectrin and calnectrin in yeast, suggesting that FsTri12p may reside in the plasma membrane in recombinant strains. The current study provides evidence for FgTri12p localization in the plasma membrane in $F$. graminearum. However, the gene also appears to have an additional regulatory function on trichothecene accumulation in $F$. graminearum. We speculate that FgTri12p may serve as part of a sensor mechanism for extracellular trichothecene levels or may affect regulation by influencing internal concentrations of $15 \mathrm{ADON}$ or trichothecene pathway intermediates.

\section{Morphological changes associated with toxin production and infection.}

Several studies indicate that cell morphology of F. graminearum noticeably changes during plant infection (Boddu et al. 2006; Brown et al. 2010; Ilgen et al. 2009; Jansen et al. 2005; Pritsch et al. 2000; Rittenour and Harris 2010). In the current study, we have observed what we believe are similar changes in vitro under trichothecene induction conditions. Subapical ovoid structures form approximately $18 \mathrm{~h}$ after suspension of conidia into TBI medium and, by $24 \mathrm{~h}$, cultures form branched hyphae with thick coralloid morphology. Disruption of FgTri12 does inhibit the observed changes in cellular morphology (data not shown). These structures are similar in shape to the bulbous or thickened coral-like hyphae described during the colonization of wheat 24 to $48 \mathrm{~h}$ after inoculation (Pritsch et al. 2000; Rittenour and Harris 2010) or those reported in lemma of barley $96 \mathrm{~h}$ after inoculation (Boddu et al. 2006). Based on their similar size (approximately $10 \mu \mathrm{m}$ ) and morphology, we propose that the vesicles of fungal cells growing within the metaxylem of wheat spikelets are analogous to the enlarged vacuoles observed within ovoid cells present in TBI cultures. These morphological changes are not observed under conditions that do not induce trichothecenes, such as in MM. TBI and MM used here are identical in chemical composition for all components except nitrogen source. Thus, the polyamine putrescine alone is responsible for inducing in vitro morphological changes and trichothecene biosynthesis. Recently, it has been shown that wheat genes implicated in polyamine biosynthesis are induced $24 \mathrm{~h}$ after inoculation with $F$. graminearum and that putrescine accumulates in wheat spikes prior to toxin production by the pathogen (Gardiner et al. 2010). It is unclear whether putrescine or other polyamines may be the sole trigger for toxin production in planta and how they may influence colonization of wheat by $F$. graminearum.

\section{Subcellular localization of Tri12p.}

In the present study, a transgenic PH-1Tri12::eGFP strain was used to track the temporal and spatial expression patterns of FgTri12p in living cells. Our results are consistent with the interpretation that FgTri12p is targeted to the plasma membrane by way of the exocytosis and then turned over, via endocytosis, to the vacuole. Tri12p::eGFP was localized sequentially as dispersed foci within a fenestrated endomembrane network; in small, highly motile vesicles; in the plasma membrane; and within the lumen of late endosomes and vacuoles (Fig. 3).The presence of bound and free eGFP in cell extracts after $36 \mathrm{~h}$ of growth in TBI medium and only free eGFP after $48 \mathrm{~h}$ is consistent with this sequence of events. 
Additionally, we observed what we interpret as the fusion of Tri12p::eGFP-containing vesicles with the plasma membrane. Lee and associates (2011) described similar localization patterns of ZRA1-GFP, a putative ABC transporter tagged with GFP in $F$. graminearum, under conditions that induce zearalenone biosynthesis. ZRA1-GFP fusion proteins were interpreted to localize initially to the plasma membrane and later to the vacuole, though the authors did not report the presence of a small, motile organelle or the fusion of GFP-labeled vesicles with the plasma membrane.

Golgi equivalents (GE) are main components of the fungal secretory system and function to modify nascent proteins derived from the endoplasmic reticulum prior to secretion (Jackson 2009). Unlike Golgi of mammalian cells, GE are not stacked but, rather, are dispersed in the cytoplasm as a network of accretions to the endomembrane system often arranged as fenestrated cisternae with tubular linkages (Rambourg et al. 2001). In filamentous fungi, GE are largely directed toward the advancing hyphal tip, moving forward with the apical nucleus (Breakspear et al. 2007). The Tri12p::eGFP-labeled structures first observed during the earliest time points after toxin induction (Fig. 3) appear in structures in the subapical region of cells, consistent with the predominant location and morphology of GE as described for Aspergillus nidulans (Pantazopoulou and Penalva 2009). The fusion of vesicles labeled with Tri12p:: eGFP with the plasma membrane suggests its delivery to the functional location of this membrane-associated protein. Nevertheless, eGFP fluorescence ultimately accumulates within the vacuolar lumen, suggesting that Tri12p::eGFP is no longer active because fluorescence is no longer associated with the membrane. Indeed, by $48 \mathrm{~h}$, Western blots indicate that eGFP protein is no longer associated with Tri12p, perhaps due to normal protein turnover.

\section{Trafficking and motility of eGFP-labeled organelles.}

Recent models have been proposed for subcellular compartmentalization of the aflatoxin biosynthetic pathway in Aspergillus parasiticus and a role for exocytosis in aflatoxin efflux (Roze et al. 2011). Vesicles called aflatoxisomes were described as the site of at least two aflatoxin biosynthetic enzymes encoded by OmtA and Ver-1 (Chanda et al. 2009). Chanda and associates (2010) proposed that exocytosis may facilitate aflatoxin efflux based on the observation that vesicles from the cytoplasm move to the inner surface of the plasma membrane during peak levels of aflatoxin synthesis in culture, and that these vesicles appear to fuse with the plasma membrane, presumably releasing their contents into the growth medium. Aflatoxin appears in discrete patches on the cell surface as determined by fluorescent antibody staining with aflatoxin specific antisera, after the peak period of aflatoxin production (Chanda et al. 2010). Additionally, exocytosis was proposed as a mechanism for aflatoxin efflux because deletion of aflT, a gene in the aflatoxin biosynthetic cluster predicted to encode an MFS transporter, does not have a significant effect on aflatoxin transport (Chang et al. 2004). Results from the current study of trichothecene biosynthesis in $F$. graminearum suggest that exocytosis may play a role in delivering FgTri12p to the plasma membrane; however, it is unclear whether it may also play an expanded role in facilitating the transport of trichothecenes across the plasma membrane.

The motility of secretory vesicles, vacuoles, Golgi elements, endoplasmic reticulum, and mitochondria in yeast is dependent on the interaction between actin and myosin (Seabra and Coudrier 2004). This interaction also influences endocytosis in A. nidulans and F. graminearum (Kim et al. 2009; Suelmann and Fischer 2000; Upadhyay and Shaw 2008). To test for the involvement of actin in the motility of eGFP-labeled vesicles in $F$. graminearum, TBI cultures of the PH-1Tri12::eGFP strain were treated with latrunculin A. After $1 \mathrm{~h}$ of exposure to latrunculin A, fluorescently labeled small, motile vesicles were completely absent in cells. eGFP fluorescence remained localized in vacuoles but appeared greater in plasma membranes of latrunculin-A-treated cells. When treated cells were washed to remove latrunculin A and returned to fresh TBI culture medium, small, motile fluorescent vesicles were evident $4 \mathrm{~h}$ after wash-out and fluorescence of the plasma membrane was reduced. We interpret these results as demonstrating a role for actin in intracellular trafficking of FgTri12p. Because of the apparent accumulation of Tri12p:eGFP in the plasma membrane of latrunculin-A-treated cells, we speculate that actin may facilitate the movement of the protein from the plasma membrane to the vacuole, presumably via endocytosis.

Further work must be conducted to determine whether the enzymes involved in trichothecene biosynthesis are localized in specialized structures similar to aflatoxisomes of Aspergillus spp. We have recently found that eGFP-tagged Tri1p, a cytochrome P-450 monoxygenase catalyzing an intermediate step in trichothecene biosynthesis, is targeted to the membrane of vesicles during the period of trichothecene accumulation in culture (J. Menke, unpublished). We are currently testing whether other enzymes of the toxin pathway may be co-localized with Trilp, supporting the idea of a trichothecene "toxisome" in Fusarium spp. How trichothecenes such as DON are translocated from their site of biosynthesis to the extracellular environment and the details of the role of Tri12p and exocytosis in this process remain to be determined.

\section{MATERIALS AND METHODS}

\section{Strains and culture conditions.}

Conidia of $F$. graminearum wild-type strain PH-1 (NRRL 31084 ) and all mutants were cultured at $25^{\circ} \mathrm{C}$ in liquid carboxymethylcellulose (CMC) medium (low-viscosity CMC [Sigma-Aldrich, St. Louis], $15.0 \mathrm{~g} ; \mathrm{NH}_{4} \mathrm{NO}_{3}, 1.0 \mathrm{~g} ; \mathrm{KH}_{2} \mathrm{PO}_{4}$, $1.0 \mathrm{~g} ; \mathrm{MgSO}_{4} \cdot 7 \mathrm{H}_{2} \mathrm{O}, 0.5 \mathrm{~g}$; and yeast extract [BD, Franklin Lakes, NJ, U.S.A.]) for 5 days. Spores were harvested by low-speed centrifugation and washed twice with sterile distilled $\mathrm{H}_{2} \mathrm{O}$. Spore concentrations were determined using a hemacytometer.

Liquid TBI medium adapted from a previous source (Gardiner et al. 2009) contained (per liter) $30 \mathrm{~g}$ of sucrose, $1 \mathrm{~g}$ of $\mathrm{KH}_{2} \mathrm{PO}_{4}, 0.5 \mathrm{~g}$ of $\mathrm{MgSO}_{4} \cdot 7 \mathrm{H}_{2} \mathrm{O}, 0.5 \mathrm{~g}$ of $\mathrm{KCl}, 10 \mathrm{mg}$ of $\mathrm{FeSO}_{4} \cdot 7 \mathrm{H}_{2} \mathrm{O}, 800 \mathrm{mg}$ of putrescine, and $200 \mu \mathrm{l}$ of trace element solution $\left(5 \mathrm{~g}\right.$ of citric acid, $5 \mathrm{~g}$ of $\mathrm{ZnSO}_{4} \cdot 7 \mathrm{H}_{2} \mathrm{O}, 0.25 \mathrm{~g}$ of $\mathrm{CuSO}_{4} 5 \mathrm{H}_{2} \mathrm{O}, 50 \mathrm{mg}$ of $\mathrm{MnSO}_{4} \cdot \mathrm{H}_{2} \mathrm{O}, 50 \mathrm{mg}$ of $\mathrm{H}_{3} \mathrm{BO}_{3}$, and $50 \mathrm{mg}$ of $\mathrm{NaMoO}_{4} \cdot 2 \mathrm{H}_{2} \mathrm{O}$ per $100 \mathrm{ml}$ ). In all cases, TBI stock medium was filtered through $0.45 \mu \mathrm{M}$ bottle-top filter sets (Corning, Corning, NY, U.S.A.). Culture plates for radial growth assays contained TBI $+1 \%$ bactoagar (BD) or $\mathrm{MM}$ (Correll et al. 1987). TBI plates were made using $2 \times$ TBI supplemented 1:1 with sterile $2 \% \mathrm{H}_{2} \mathrm{O}$ agar. The $2 \times$ TBI solution was adjusted to $\mathrm{pH} 4.5$ with $\mathrm{NaOH}$ before dilution.

\section{Protoplasts and transformation.}

In all, $1 \mathrm{ml}$ of washed conidia $\left(10^{8} \mathrm{ml}^{-1}\right)$ harvested from a 5-day-old CMC culture was used to inoculate a 100-ml culture (yeast extract, $3.0 \mathrm{~g}$; Bactopeptone [BD], $10.0 \mathrm{~g}$; glucose, 20.0 $\mathrm{g}$; and distilled water to 1 liter) that was incubated for 16 to 18 $\mathrm{h}$ at room temperature with shaking at $150 \mathrm{rpm}$. Tissue present after incubation was used to prepare protoplasts. Protoplast preparation and fungal transformation were performed as described previously (Hou et al. 2002). 
Targeted gene disruption and ectopic gene insertion.

Tri12 deletion mutants were generated in the wild-type strain PH-1 by split-marker recombination mutagenesis (Catlett et al. 2003) with previously described modifications (Goswami et al. 2006). DNA oligonucleotides (IDT Inc., Coralville, IA, U.S.A.) listed in Supplementary Table S5 were used to PCR amplify 5' and $3^{\prime}$ flanking regions beginning $934 \mathrm{bp}$ and ending $23 \mathrm{bp} 5^{\prime}$ of the FgTril2 start codon $(911 \mathrm{bp})$ and the region $510 \mathrm{bp} 5^{\prime}$ and 455 bp $3^{\prime}$ of the TAA stop codon (968 bp) using PH-1 genomic DNA as a template. The right and left flanks of $h p h$ were amplified using oligonucleotides and the plasmid pCX62 (Zhao et al. 2004), which contains the hph gene, as a template.

Hygromycin-resistant transformants were isolated and gene replacement and ectopic mutations were confirmed with Southern hybridization. V8 juice agar (200 $\mathrm{ml}$ of V8 juice [Campbell Soup Company, Camden, NJ, U.S.A.], $2 \mathrm{~g}$ of $\mathrm{CaCO}_{3}, 15 \mathrm{~g}$ of agar, and water to 1 liter) supplemented with hygromycin $\mathrm{B}$ (250 $\mu \mathrm{g} \mathrm{ml}^{-1}$ ) (Calbiochem, La Jolla, CA, U.S.A.) was used for selection of transformants. RT-PCR was used to confirm the absence or presence of FgTril2 transcripts in disruption or ectopic mutant strains. To determine whether reduced trichothecene accumulation may be due to alteration of the Trill promoter, the entire $5^{\prime}$ untranslated region of Trill from the three Fgtri12 deletion mutants was sequenced and compared with the similarly sequenced region of Trill in wild-type PH-1. No DNA sequence differences in the Trill promoter were noted between $\mathrm{PH}-1$ and. $\mathrm{PH}-1$ tri12A. $\mathrm{PH}-1$ tri12B and $\mathrm{PH}-1$ tri12C contained small nucleotide differences compared with $\mathrm{PH}-1$. There were three transitional $(\mathrm{A} \rightarrow \mathrm{G})$ single-nucleotide proteins (SNP) in PH-1tri12B, one of which occurred 2 bp $3^{\prime}$ of the farthest upstream predicted Tri6p-binding site for Tril1. A single transitional $(\mathrm{T} \rightarrow \mathrm{C}) \mathrm{SNP}$ occurred in the $\mathrm{PH}-1$ tri12C mutant $119 \mathrm{bp}$ downstream of the farthest upstream predicted Tri6p-binding site for Trill and 193 bp upstream of the other predicted Tri6p-binding site for Tril1. These results do not support the conclusion that altered trichothecene accumulation is due to alteration of the Trill promoter.

\section{eGFP tagging.}

A fusion PCR-based method (Szewczyk et al. 2006) was used with modification to synthesize the construct used to generate FgTri12::eGFP. The Neurospora knock-in vector (Honda and Selker 2009) pGFP::hph::loxP (GenBank: FJ457011.1) was used as a template for the synthesis of the eGFP::hph portion of the fusion constructs. Hygromycin-resistant transformants were isolated and gene tagging was confirmed by Southern hybridization. V8 juice agar supplemented with hygromycin B at $250 \mu \mathrm{g} \mathrm{ml}^{-1}$ was used for isolation of transformants. Western blotting was used to confirm the presence of eGFP-tagged fusion proteins in cellular extracts.

\section{Nucleic acid extraction, Southern blotting, cDNA sequencing, and RT-PCR.}

Tissue for DNA extraction was cultured in complete medium (Trail et al. 2003) for 7 days at $25^{\circ} \mathrm{C}$. Cultures were washed twice with double-distilled $\mathrm{H}_{2} \mathrm{O}$ and freeze dried. Genomic DNA was extracted from dried cultures using a commercial product (Omniprep DNA kit; G Biosciences, Maryland Heights, MO, U.S.A.). Genomic DNA used for Southern blotting was treated with RNAse A at room temperature for 15 min before digestion. Genomic DNA (20 $\mu \mathrm{g} / \mathrm{sample})$ was digested with $P s t \mathrm{I}$ or $B g l \mathrm{II}$. DNA probes were used to detect the presence of $h p h, e G F P$, and Tril2 in the appropriate fungal strains via Southern hybridization using DNA oligonucleotides to synthesize the probes. Southern hybridization was performed as described previously (Rosewich et al. 1998), except probe hybridization and primary wash temperatures were increased to $65^{\circ} \mathrm{C}$. The Amersham AlkPhos direct labeling and detection system with CDP-Star (GE Healthcare, Piscataway, NJ, U.S.A.) was used to label and detect the DNA probes.

For RNA extraction, biomass from TBI cultures was harvested by filtration with Miracloth and washed twice with sterile distilled water. Tissue was flash frozen in liquid nitrogen and lyophilized for $24 \mathrm{~h}$. Dried tissue was ground in liquid nitrogen before RNA extraction. RNA was isolated from fungal tissue using TRIzol reagent (Life Technologies, Inc., Carlsbad, CA, U.S.A.) and the RNeasy mini total RNA extraction kit (Qiagen, Valencia, CA, U.S.A.) according to the manufacturers' protocol.

To generate template DNA molecules for gene-specific PCR, 3' RACE-PCR was used. mRNA extracted from inoculated plants was used for cDNA synthesis. A universal cDNA cloning oligonucleotide was used to prime cDNA synthesis reactions. A 3' RACE-PCR oligonucleotide designed to anneal to the $5^{\prime}$ end of synthesized cDNA and the gene-specific oligonucleotide 1 Fwd were used to generate PCR products used as templates for sequencing. These products were sequenced with the oligonucleotides shown above the proposed gene model for FgTril2. PCR products were sequenced using a BigDye Terminator v3.1 cycle sequencing kit. (Life Technologies, Inc.). FinchTV (Geospiza, Inc., Seattle) was used to edit sequencing traces. Sequence trace alignments were generated using Sequencher 4.7 (Gene Codes Corp, Ann Arbor, MI, U.S.A.). Reference genomic DNA sequence for $F g$ Tril2 was obtained from MIPS. Comparison of DNA sequences was conducted using a Smith-Waterman local alignment tool hosted by the European Bioinformatics Institute website (Smith and Waterman 1981). Predicted protein sequences were compared as previously described using the Needle alignment tool included in The European Molecular Biology Open Software Suite website (Needleman and Wunsch 1970; Rice et al. 2000). Transmembrane domain predictions were conducted using TMPred (Hofmann and Stoffel 1993) implemented via the EMBnet website.

RT-PCR was used to detect the presence or absence of FgTril2 transcripts in $\mathrm{PH}-1, \mathrm{PH}-1$ tri12A, $\mathrm{PH}-$ tri12B, $\mathrm{PH}-$ 1 tri12C, or PH-1ectopic strains grown in liquid TBI cultures for $24 \mathrm{~h}$. Oligo pairs designed to amplify a 124-bp region of FgTril2 cDNA or a 94-bp region of $\beta$-tubulin cDNA were used to assay reverse-transcriptase cDNA preparations via PCR. SuperScript III reverse transciptase (Life Technologies, Inc.) was used in all cDNA synthesis reactions.

\section{Protein extraction and Western blotting.}

Conidia of PH-1Tri12::eGFP were suspended in $100-\mathrm{ml}$ TBI cultures at a final concentration of $2 \times 10^{4}$ conidia ml ${ }^{-1}$ and incubated at $28^{\circ} \mathrm{C}$ on an orbital shaker rotating at $150 \mathrm{rpm}$ in total darkness. Mycelia were separated from culture medium via filtration through two-ply Miracloth after 24, 30, 36, and $48 \mathrm{~h}$ of incubation. Mycelia were washed twice with $50 \mathrm{ml}$ of sterile $\mathrm{H}_{2} \mathrm{O}$, blotted with filter paper to remove excess $\mathrm{H}_{2} \mathrm{O}$, flash frozen in liquid nitrogen, and lyophilized to dryness. A Mem-PER eukaryotic membrane protein extraction kit (Thermo Fisher Scientific, Rockford, IL, U.S.A.) was used to extract protein from lyophilized tissue with minor modifications to the recommended protocol. The ratio of hydrophobic/hydrophilic extraction buffers was adjusted to $1: 1$ instead of the recommended 3:1 ratio. The hydrophilic fraction of the protein extraction cocktail was separated from the hydrophilic fraction, diluted threefold in the recommended diluent, diluted 50:50 with Laemmli sample buffer amended with 5\% $\beta \mathrm{ME}$, and run on 4 to $20 \%$ Tris-HCl Ready gel precast gels (Bio-Rad, Hercules, CA, U.S.A.). Separated proteins were transferred to Immun-Blot polyvinylidene diflouride membranes (Bio-Rad) for Western blotting. Blotted membranes were probed sequentially 
with a primary goat anti-GFP polyclonal antibody and a secondary rabbit anti-goat immunoglobulin G HRP antibody (Santa Cruz Biotechnology, Santa Cruz, CA, U.S.A.). Probed blots were developed with Pierce ECL Plus Western blotting substrate (Thermo Fisher Scientific) and imaged using a Carestream Image Station 4000MM PRO imaging system (Carestream, Rochester, NY, U.S.A.).

\section{Pathogenicity and trichothecene assays.}

Wheat plants (Triticum aestivum 'Norm') were grown as previously described (Goswami and Kistler 2005). The fifth spikelet from the first fully developed basal spikelet was inoculated with $10 \mu \mathrm{l}$ of a conidial suspension of $10^{5}$ conidia $\mathrm{ml}^{-1}+0.1 \%$ Triton X100 after the awns were removed. After inoculation, wheat plants were placed in a humidity chamber for $48 \mathrm{~h}$. Plants were then transferred to a lighted growth chamber and grown for an additional 8 days. Plants were exposed to a repeating 16-h (day) and 8-h (night) diurnal cycle, with day and night temperatures maintained at 18 and $16^{\circ} \mathrm{C}$, respectively. For pathogenicity determination, mycotoxin measurement, and average mass of infected spike measurements, singlepoint inoculated spikes were scored for disease at 10 days after inoculation and then collected, weighed, and stored at $-20^{\circ} \mathrm{C}$. The five upper and four lower spikelets adjacent to the inoculated spikelet, as well as the inoculated spikelet itself, were scored for disease symptoms. Quantification of DON and $15 \mathrm{ADON}$ in inoculated spikelets was conducted as previously described (Goswami and Kistler 2005). Four independent assays of pathogenicity and trichothecene accumulation in planta were conducted for $\mathrm{PH}-1, \mathrm{PH}-1$ tri12A, $\mathrm{PH}-1$ tri12B, Tri12C, and PH-1ectopic, each with 10 inoculated spikes, whereas three independent assays were conducted for PH-1 and PH-1Tri12::eGFP. A Kruskal-Wallis test indicated that the mean number of symptomatic spikes was significantly different among $\mathrm{PH}-1, \mathrm{PH}-1$ tri12A, $\mathrm{PH}-1$ tri12B, Tri12C, and $\mathrm{PH}-1 e c$ topic $(P<0.01)$. Mann-Whitney $\mathrm{U}$ tests were used for pairwise comparisons. This test indicated no significant difference in the mean number of symptomatic spikes among $\mathrm{PH}-1$ and $\mathrm{PH}-$ 1Tri12::eGFP. A one-way analysis of variance (ANOVA) indicated that mean trichothecene accumulation in planta was significantly different among $\mathrm{PH}-1, \mathrm{PH}-1$ tri12A, $\mathrm{PH}-1$ tri12B, Tri12C, and PH-1ectopic $(P<0.0001)$. Student's unpaired $t$ test was used for pairwise comparisons between strains. This test indicated no significant difference in mean trichothecene accumulation by PH-1 and PH-1Tri12::eGFP in planta.

Stationary liquid TBI cultures $(2 \mathrm{ml})$ inoculated with $10^{4} \mathrm{ml}^{-1}$ conidia were used to assay trichothecene accumulation in vitro. Cultures were grown at $25^{\circ} \mathrm{C}$ in total darkness for 7 days. Culture medium was filtered through cheesecloth to remove fungal tissue and freeze dried. Dried samples were analyzed for the presence of DON and 15ADON as previously described (Goswami and Kistler 2005). Three independent assays of trichothecene accumulation in vitro were conducted for all strains. Assays for P PH-1, PH-1tri12A, PH-1tri12B, Tri12C, and PH1ectopic surveyed four independent cultures for each strain, whereas assays performed for $\mathrm{PH}-1$ and $\mathrm{PH}-1$ Tri12::eGFP surveyed six independent cultures for each strain.

A one-way ANOVA indicated that mean trichothecene accumulation was significantly different among PH-1, PH-1tri12A, PH-1tri12B, Tri12C, and PH-1ectopic $(P<0.0001)$. Student's unpaired $t$ tests was used for pairwise comparisons. This test indicated no significant difference in mean trichothecene accumulation by PH-1 and PH-1Tri12::eGFP.

\section{Radial growth on TBI and MM agar.}

Cultures for radial growth assays were grown in 60-by-15$\mathrm{mm}$ petri dishes containing $10 \mathrm{-ml}$ aliquots of TBI agar at $25^{\circ} \mathrm{C}$ with a 12-h light-and-dark diurnal cycle. Test cultures were independently inoculated at the center of the plate with 4-mm plugs of each strain. Circular plugs were cut from the leading edge of growth on MM agar source plates and placed tissueside down on test plates. The average diameter of each colony was determined using four independent diameter measurements fixed to the culture plate. The results of six plates were used to determine the average colony diameter for $\mathrm{PH}-1, \mathrm{PH}-$ 1tri12A, PH-1tri12B, Tri12C, and PH-1ectopic at 24, 48, 72, and $96 \mathrm{~h}$ after inoculation, whereas three plates were used to compare PH-1 and PH-1Tri12::eGFP. Two independent radial growth assays were conducted for $\mathrm{PH}-1, \mathrm{PH}-1$ tri12A, $\mathrm{PH}-1-$ tri12B, Tri12C, and $\mathrm{PH}-1$ ectopic, whereas three independent assays were conducted for PH-1 and PH-1Tri12::eGFP. A oneway ANOVA indicated that mean colony diameters of assayed strains were significantly different $(P<0.0001)$. Student's unpaired $t$ test was used for pairwise comparisons. This test indicated no significant difference in mean radial growth of $\mathrm{PH}-1$ and PH-1Tri12::eGFP. As a non-toxin control, additional cultures used for the observation of radial growth were grown in 100-by-15-mm petri dishes containing $20 \mathrm{ml}$ of MM agar.

\section{Bright-field, DIC, fluorescence, and laser scanning fluorescence confocal microscopy.}

To observe changes in cell morphology, $\mathrm{PH}-1$ was grown in $50 \mathrm{ml}$ of liquid $\mathrm{MM}$ or $\mathrm{TBI}$ medium at $25^{\circ} \mathrm{C}$ on an orbital shaker rotating at $150 \mathrm{rpm}$ in total darkness. Cultures were sampled at $12,16,18$, and $24 \mathrm{~h}$ following inoculation with $5 \times$ $10^{5}$ conidia. To observe Tri12p::eGFP in vivo, $50-\mathrm{ml}$ TBI cultures were grown at $28^{\circ} \mathrm{C}$ on an orbital shaker rotating at 150 $\mathrm{rpm}$ in total darkness. Cultures were sampled over a 44-h period following inoculation with $5 \times 10^{5}$ conidia. Wet mounts of tissue were viewed using a Nikon Eclipse 90i upright microscope and a Nikon C1si laser-scanning confocal microscope. Spectral unmixing of autofluorescence and GFP signals was conducted using known spectra for GFP (Clontech, Mountain View, CA, U.S.A.). Regions of autofluorescence were selected in the untagged PH-1 strain using the Nikon EZ-C1 Viewer. Laser-scanning confocal microscopy and spectral unmixing were used to confirm that the spectrum of fluorescence emitted from fungal cells matched the emission spectrum of eGFP (data not shown).

Mycelia from 42-h cultures of FgTri12::eGFP strains were stained with CellTracker Blue CMAC (Life Technologies, Inc.) to identify late endosomes and vacuoles. CMAC dye was dissolved in DMSO immediately before use. Addition of the dye solution to culture samples resulted in a final concentration of $100 \mu \mathrm{M} \mathrm{CMAC}$ and $1 \%$ DMSO. Stained cells were viewed $30 \mathrm{~min}$ after exposure to the dye.

\section{Treatment of cells with latrunculin A.}

Latrunculin A was used to establish the involvement of actin microfilaments in the cellular fate of Tri12p::eGFP. Conidia of PH-1Tri12::eGFP were suspended in $20-\mathrm{ml}$ TBI cultures at a final concentration of $10^{4}$ conidia $\mathrm{ml}^{-1}$ and incubated at $28^{\circ} \mathrm{C}$ on an orbital shaker rotating at $150 \mathrm{rpm}$ in total darkness. After $36 \mathrm{~h}$ of incubation, samples from pretreated culture samples were plated on recovery medium (per liter: sucrose, $30 \mathrm{~g}$; $\mathrm{KH}_{2} \mathrm{PO}_{4}, 1 \mathrm{~g} ; \mathrm{MgSO}_{4} \cdot 7 \mathrm{H}_{2} \mathrm{O}, 0.5 \mathrm{~g} ; \mathrm{KCl}, 0.5 \mathrm{~g} ; \mathrm{FeSO}_{4} \cdot 7 \mathrm{H}_{2} \mathrm{O}$, $10 \mathrm{mg} ; \mathrm{NaNO}_{3}, 850 \mathrm{mg}$; and $200 \mu \mathrm{l}$ of trace element solution [per $100 \mathrm{ml}$ : citric acid, $5 \mathrm{~g} ; \mathrm{ZnSO}_{4} \cdot 7 \mathrm{H}_{2} \mathrm{O}, 5 \mathrm{~g} ; \mathrm{CuSO}_{4} 5 \mathrm{H}_{2} \mathrm{O}$, $0.25 \mathrm{~g} ; \mathrm{MnSO}_{4} \cdot \mathrm{H}_{2} \mathrm{O}, 50 \mathrm{mg} ; \mathrm{H}_{3} \mathrm{BO}_{3}, 50 \mathrm{mg}$; and $\mathrm{NaMoO}_{4}$ $\left.\left.2 \mathrm{H}_{2} \mathrm{O}, 50 \mathrm{mg}\right]\right)$. Cultures were then treated with latrunculin A (Enzo Life Sciences, Plymouth Meeting, PA, U.S.A.) in DMSO (Sigma-Aldrich) or DMSO alone and incubated under the same conditions for $1 \mathrm{~h}$. After treatment, cultures contained a final concentration of latrunculin $\mathrm{A}$ at $5 \mu \mathrm{g} \mathrm{ml}^{-1}$ and $0.1 \%$ 
DMSO or $0.1 \%$ DMSO only. After incubation, samples were removed for microscopy and plated on recovery medium. Tissue was then filtered from the test cultures and washed with four volumes of $20 \mathrm{ml}$ of TBI medium. Tissue was resuspended in $25 \mathrm{ml}$ of TBI medium and incubated for an additional $4 \mathrm{~h}$, when samples were examined by microscopy or plated on recovery medium and incubated overnight at $25^{\circ} \mathrm{C}$.

\section{ACKNOWLEDGMENTS}

We thank K. Broz for outstanding technical support and M. Sanders and the University of Minnesota Imaging Core Facility for helpful discussions. This work was funded by the United States Department of Agriculture, United States Wheat and Barley Scab Initiative awards FY09-KI-016, FY08-KI-118, and FY07-KI-125.

\section{LITERATURE CITED}

Alexander, N. J., McCormick, S. P., and Hohn, T. M. 1999. TRI12, a trichothecene efflux pump from Fusarium sporotrichioides: Gene isolation and expression in yeast. Mol. Gen. Genet. 261:977-984.

Alexander, N. J., McCormick, S. P., Waalwijk, C., van der Lee, T., and Proctor, R. H. 2011. The genetic basis for 3-ADON and 15-ADON trichothecene chemotypes in Fusarium. Fungal Genet. Biol. 48:485-495.

Bai, G. H., Desjardins, A. E., and Plattner, R. D. 2002. Deoxynivalenolnonproducing Fusarium graminearum causes initial infection, but does not cause disease spread in wheat spikes. Mycopathologia 153:91-98.

Boddu, J., Cho, S., Kruger, W. M., and Muehlbauer, G. J. 2006. Transcriptome analysis of the barley-Fusarium graminearum interaction. Mol. Plant-Microbe Interact. 19:407-417.

Breakspear, A., Langford, K. J., Momany, M., and Assinder, S. J. 2007. CopA: GFP localizes to putative Golgi equivalents in Aspergillus nidulans. FEMS (Fed. Eur. Microbiol. Soc.) Microbiol. Lett. 277:90-97.

Brown, N. A., Urban, M., Van De Meene, A. M. L., and HammondKosack, K. E. 2010. The infection biology of Fusarium graminearum: Defining the pathways of spikelet to spikelet colonisation in wheat ears. Fungal Biol. 114:555-571.

Callahan, T. M., Rose, M. S., Meade, M. J., Ehrenshaft, M., and Upchurch, R G. 1999. CFP, the putative cercosporin transporter of Cercospora kikuchii, is required for wild type cercosporin production, resistance, and virulence on soybean. Mol. Plant-Microbe Interact. 12:901-910.

Catlett, N. L., Lee, B. N., Yoder, O. C., and Turgeon, B. G. 2003. Splitmarker recombination for efficient targeted deletion of fungal genes. Fungal Genet. Newsl. 50:9-11.

Chanda, A., Roze, L. V., Kang, S., Artymovich, K. A., Hicks, G. R., Raikhel, N. V., Calvo, A. M., and Linz, J. E. 2009. A key role for vesicles in fungal secondary metabolism. Proc. Natl. Acad. Sci. U.S.A. 106:19533-19538.

Chanda, A., Roze, L. V., and Linz, J. E. 2010. A possible role for exocytosis in aflatoxin export in Aspergillus parasiticus. Eukaryot. Cell 9:17241727.

Chang, P. K., Yu, J. J., and Yu, J. H. 2004. aflT, a MFS transporter-encoding gene located in the aflatoxin gene cluster, does not have a significant role in aflatoxin secretion. Fungal Genet. Biol. 41:911-920.

Choquer, M., Lee, M. H., Bau, H. J., and Chung, K. R. 2007. Deletion of a MFS transporter-like gene in Cercospora nicotianae reduces cercosporin toxin accumulation and fungal virulence. FEBS (Fed. Eur. Biochem. Soc.) Lett. 581:489-494.

Coleman, J. J., and Mylonakis, E. 2009. Efflux in fungi: La piece de resistance. PLOS Pathog. 5:7.

Coleman, J. J., White, G. J., Rodriguez-Carres, M., and VanEtten, H. D. 2011. An ABC transporter and a cytochrome P450 of Nectria haematococca MPVI are virulence factors on pea and are the major tolerance mechanisms to the phytoalexin pisatin. Mol. Plant-Microbe Interact. 24:368-376.

Correll, J. C., Klittich, C. J. R., and Leslie, J. F. 1987. Nitrate nonutilizing mutants of Fusarium oxysporum and their use in vegetative compatibility tests. Phytopathology 77:1640-1646.

Cuomo, C. A., Güldener, U., Xu, J. R., Trail, F., Turgeon, B. G., Di Pietro, A., Walton, J. D., Ma, L. J., Baker, S. E., Rep, M., Adam, G., Antoniw, J., Baldwin, T., Calvo, S., Chang, Y. L., DeCaprio, D., Gale, L. R., Gnerre, S., Goswami, R. S., Hammond-Kosack, K., Harris, L. J., Hilburn, K., Kennell, J. C., Kroken, S., Magnuson, J. K., Mannhaupt, G., Mauceli, E., Mewes, H. W., Mitterbauer, R., Muehlbauer, G., Munsterkotter, M., Nelson, D., O'Donnell, K., Ouellet, T., Qi, W. H., Quesneville, H., Roncero, M. I. G., Seong, K. Y., Tetko, I. V., Urban, M., Waalwijk, C., Ward, T. J., Yao, J. Q., Birren, B. W., and Kistler, H. C. 2007. The
Fusarium graminearum genome reveals a link between localized polymorphism and pathogen specialization. Science 317:1400-1402.

Gardiner, D. M., Kazan, K., and Manners, J. M. 2009. Nutrient profiling reveals potent inducers of trichothecene biosynthesis in Fusarium graminearum. Fungal Genet. Biol. 46:604-613.

Gardiner, D. M., Kazan, K., Praud, S., Torney, F. J., Rusu, A., and Manners, J. M. 2010. Early activation of wheat polyamine biosynthesis during Fusarium head blight implicates putrescine as an inducer of trichothecene mycotoxin production. BMC Plant Biol. 10:13.

Goswami, R. S., and Kistler, H. C. 2005. Pathogenicity and in planta mycotoxin accumulation among members of the Fusarium graminearum species complex on wheat and rice. Phytopathology 95:1397-1404.

Goswami, R. S., Xu, J. R., Trail, F., Hilburn, K., and Kistler, H. C. 2006. Genomic analysis of host-pathogen interaction between Fusarium graminearum and wheat during early stages of disease development. Microbiol.-Sgm 152:1877-1890.

Güldener, U., Mannhaupt, G., Munsterkotter, M., Haase, D., Oesterheld, M., Stumpflen, V., Mewes, H.W., and Adam, G. 2006. FGDB: A comprehensive fungal genome resource on the plant pathogen Fusarium graminearum. Nucleic Acids Res. 34:D456-D458.

Han, Y. N., Liu, X. G., Benny, U., Kistler, H. C., and VanEtten, H. D. 2001. Genes determining pathogenicity to pea are clustered on a supernumerary chromosome in the fungal plant pathogen Nectria haematococca. Plant J. 25:305-314.

Hofmann, K., and Stoffel, W. 1993. TMbase-a database of membrane spanning protein segments. Biol. Chem. Hoppe Seyler 374:166.

Hollingsworth, C. R., Motteberg, C. D., Wiersma, J. V., and Atkinson, L. M. 2008. Agronomic and economic responses of spring wheat to management of Fusarium head blight. Plant Dis. 92:1339-1348.

Honda, S., and Selker, E. U. 2009. Tools for Fungal Proteomics: Multifunctional Neurospora vectors for gene replacement, protein expression and protein purification. Genetics 182:11-23.

Hou, Z. M., Xue, C. Y., Peng, Y. L., Katan, T., Kistler, H. C., and Xu, J. R. 2002. A mitogen-activated protein kinase gene (MGV1) in Fusarium graminearum is required for female fertility, heterokaryon formation, and plant infection. Mol. Plant-Microbe Interact. 15:1119-1127.

Ilgen, P., Hadeler, B., Maier, F. J., and Schafer, W. 2009. Developing kernel and rachis node induce the trichothecene pathway of Fusarium graminearum during wheat head infection. Mol. Plant-Microbe Interact. 22:899-908.

Jackson, C. L. 2009 Mechanisms of transport through the Golgi complex. J. Cell Sci. 122:443-452.

Jansen, C., von Wettstein, D., Schafer, W., Kogel, K. H., Felk, A., and Maier, F. J. 2005. Infection patterns in barley and wheat spikes inoculated with wild-type and trichodiene synthase gene disrupted Fusarium graminearum. Proc. Natl. Acad. Sci. U.S.A. 102:16892-16897.

Kim, J. E., Lee, H. J., Lee, J., Kim, K. W., Yun, S. H., Shim, W. B., and Lee, Y. W. 2009. Gibberella zeae chitin synthase genes, GzCHS5 and $\mathrm{GzCHS7}$, are required for hyphal growth, perithecia formation, and pathogenicity. Curr. Genet. 55:449-459.

Kimura, M., Tokai, T., Takahashi-Ando, N., Ohsato, S., and Fujimura, M. 2007. Molecular and genetic studies of Fusarium trichothecene biosynthesis: Pathways, genes, and evolution. Biosci. Biotechnol. Biochem. 71:2105-2123.

Lee, S., Son, H., Lee, J., Lee, Y. R., and Lee, Y. W. 2011. A putative ABC transporter gene, ZRA1, is required for zearalenone production in Gibberella zeae. Curr. Genet. 57:343-351.

Lee, T., Han, Y. K., Kim, K. H., Yun, S. H., and Lee, Y. W. 2002. Tri13 and Tri7 determine deoxynivalenol- and nivalenol-producing chemotypes of Gibberella zeae. Appl. Environ. Microbiol. 68:2148-2154.

McMullen, M., Jones, R., and Gallenberg, D. 1997. Scab of wheat and barley: A re-emerging disease of devastating impact. Plant Dis. 81:13401348

Needleman, S. B., and Wunsch, C. D. 1970. A general method applicable to the search for similarities in the amino acid sequences of two proteins. J. Mol. Biol. 48: 443-453.

Pantazopoulou, A., and Penalva, M. A. 2009. Organization and dynamics of the Aspergillus nidulans Golgi during apical extension and mitosis. Mol. Biol. Cell 20:4335-4347.

Pasrija, R., Banerjee, D., and Prasad, R. 2007. Structure and function analysis of CaMdr1p, a major facilitator superfamily antifungal efflux transporter protein of Candida albicans: Identification of amino acid residues critical for drug/H+ transport. Eukaryot. Cell 6:443-453.

Pitkin, J. W., Panaccione, D. G., and Walton, J. D. 1996. A putative cyclic peptide efflux pump encoded by the TOXA gene of the plant-pathogenic fungus Cochliobolus carbonum. Microbiol.-UK 142:1557-1565.

Pritsch, C., Muehlbauer, G. J., Bushnell, W. R., Somers, D. A., and Vance, C. P. 2000. Fungal development and induction of defense response genes during early infection of wheat spikes by Fusarium graminearum. Mol. Plant-Microbe Interact. 13:159-169. 
Proctor, R. H., Hohn, T. M., McCormick, S. P., and Desjardins, A. E 1995. TRI6 encodes an unusual zinc-finger protein involved in regulation of trichothecene biosynthesis in Fusarium sporotrichioides. Appl. Environ. Microbiol. 61:1923-1930.

Rambourg, A., Jackson, C. L., and Clermont, Y. 2001. Three dimensional configuration of the secretory pathway and segregation of secretion granules in the yeast Saccharomyces cerevisiae. J. Cell Sci. 114:22312239.

Rep, M., and Kistler, H. C. 2010. The genomic organization of plant pathogenicity in Fusarium species. Curr. Opin. Plant Biol. 13:420-426.

Rice, P., Longden, I., and Bleasby, A. 2000. EMBOSS: The European molecular biology open software suite. Trends Genet. 16:276-277.

Rittenour, W. R., and Harris, S. D. 2010. An in vitro method for the analysis of infection-related morphogenesis in Fusarium graminearum. Mol. Plant Pathol. 11:361-369.

Rosewich, U. L., Pettway, R. E., McDonald, B. A., Duncan, R. R., and Frederiksen, R. A. 1998. Genetic structure and temporal dynamics of a Colletotrichum graminicola population in a sorghum disease nursery. Phytopathology 88:1087-1093.

Roze, L. V., Chanda, A., and Linz, J. E. 2011. Compartmentalization and molecular traffic in secondary metabolism: A new understanding of established cellular processes. Fungal Genet. Biol. 48:35-48.

Seabra, M. C., and Coudrier, E. 2004. Rab GTPases and myosin motors in organelle motility. Traffic 5:393-399.

Seong, K. Y., Pasquali, M., Zhou, X. Y., Song, J., Hilburn, K., McCormick, S., Dong, Y. H., Xu, J. R., and Kistler, H. C. 2009. Global gene regulation by Fusarium transcription factors Tri6 and Tri10 reveals adaptations for toxin biosynthesis. Mol. Microbiol. 72:354-367.

Smith, T. F., and Waterman, M. S. 1981. Identification of common molecular subsequences. J. Mol. Biol. 147:195-197.

Suelmann, R., and Fischer, R. 2000. Mitochondrial movement and morphology depend on an intact actin cytoskeleton in Aspergillus nidulans. Cell Motil. Cytoskelet. 45:42-50.

Szewczyk, E., Nayak, T., Oakley, C. E., Edgerton, H., Xiong, Y., TaheriTalesh, N., Osmani, S. A., and Oakley, B. R. 2006. Fusion PCR and gene targeting in Aspergillus nidulans. Nat. Protocols 1:3111-3120.

Trail, F., Xu, J. R., San Miguel, P., Halgren, R. G., and Kistler, H. C. 2003. Analysis of expressed sequence tags from Gibberella zeae (anamorph Fusarium graminearum). Fungal Genet. Biol. 38:187-197.

Upadhyay, S., and Shaw, B. D. 2008. The role of actin, fimbrin and endocytosis in growth of hyphae in Aspergillus nidulans. Mol. Microbiol. 68:690-705.

Ward, T. J., Bielawski, J. P., Kistler, H. C., Sullivan, E., and O'Donnell, K. 2002. Ancestral polymorphism and adaptive evolution in the trichothecene mycotoxin gene cluster of phytopathogenic Fusarium. Proc. Natl. Acad. Sci. U.S.A. 99:9278-9283.

Wong, P., Walter, M., Lee, W., Mannhaupt, G., Munsterkotter, M., Mewes, H. W., Adam, G., and Güldener, U. 2011. FGDB: Revisiting the genome annotation of the plant pathogen Fusarium graminearum. Nucleic Acids Res. 39:D637-D639.

Zhao, X., Xue, C., Kim, Y., and Xu, J. R. 2004. A ligation-PCR approach for generating gene replacement constructs in Magnaporthe grisea. Fungal Genet. Newsl. 51:17-18.

\section{AUTHOR-RECOMMENDED INTERNET RESOURCES}

Broad Institute Fusarium Comparative database: www.broadinstitute.org/annotation/genome/fusarium_group/ MultiHome.html

EMBnet Transmembrane domain predictions (TMPred) database: www.ch.embnet.org

European Bioinformatics Institute, Smith-Waterman local alignment tool: www.ebi.ac.uk/Tools/emboss/align

The European Molecular Biology Open Software Suite (EMBOSS) Needle Protein Sequence Comparison site: emboss.bioinformatics.nl

Munich Information Center for Protein Sequences (MIPS) Fusarium graminearum genome database: mips.helmholtz-muenchen.de/genre/proj/FGDB 